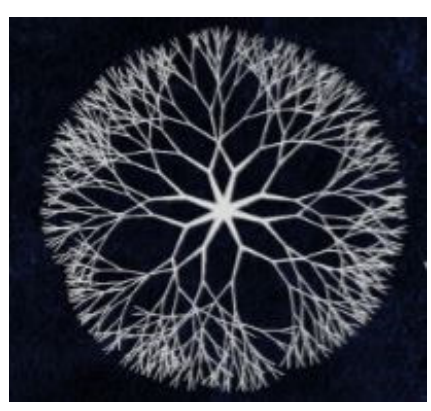

\title{
Curso Experimental de Medicina na FMUSP e suas conjecturas de implementação
}

\author{
Patrícia Teixeira Tavano \\ Doutora em Educação - FEUSP \\ patricia@tavano.net
}

\author{
Maria Isabel de Almeida \\ Livre Docente em Didática - FEUSP \\ mialmei@usp.br
}

Recebido em 29/05/2017. Aprovado em 25/06/2017.

Como citar este artigo: Tavano, P. T.; Almeida, M. I. "Curso Experimental de Medicina da FMUSP e suas conjeturas de implementação”. Khronos, Revista de História da Ciência, n4, p. 84-101. 2017. Disponível em $<$ http://revistas.usp.br/khronos $>$. Acesso em dd/mm/aaaa.

Resumo: No ano de 1968, a Faculdade de Medicina da USP iniciou uma experiência educacional designada Curso Experimental de Medicina (CEM). Oferecido concomitante ao seu curso médico convencional, o CEM trazia uma proposta curricular distinta, organizando os conteúdos em blocos, integrando-os verticalmente, inserindo os estudantes mais precocemente na prática clínica e introduzindo a atenção primária e secundária como parte do percurso formativo. Este artigo é baseado em tese de doutorado apresentada à Faculdade de Educação da USP e busca recuperar os protagonistas propositores e as contingências de proposição do CEM, tendo como base a análise de documentos escritos e orais.

Palavras-chave: Curso Experimental de Medicina, Faculdade de Medicina da USP, Educação em Saúde, Currículo médico.

\section{Experimental Medicine Course at FMUSP and its implementation conjetures}

\begin{abstract}
In the year of 1968, the USP Medicine School began an educational experience designated Experimental Medical Course (CEM). Concomitant to the medical course offered, the CEM would bring a distinctive curriculum proposal, arranging the contents in blocks, integrating them vertically, inserting students in early clinical practice and introducing primary and secondary attention as part of the training course. This article is based on the doctoral thesis submitted to the College of Education of the University of São Paulo and seeks to recover the protagonist proponents and the contingencies of CEM proposition, based on the analysis of written and oral documents.
\end{abstract}

Keywords: Experimental Medical Course, USP Medicine School, Health education, Medical curriculum. 


\section{Introdução}

No ano de 1968, a Faculdade de Medicina da Universidade de São Paulo (FMUSP) dá início a uma experiência curricular, colocando em funcionamento um curso de medicina com organização e conceituação diferenciada. Denominado Curso Experimental de Medicina (CEM), este Curso formou apenas 8 turmas e foi encerrado em 1975. O CEM não substituiu o curso médico que era oferecido pela FMUSP e sim coexistiu, concomitante, com o curso convencional que ficou conhecido então como Curso Tradicional de Medicina (CTM).

O CTM tinha como características um currículo organizado em disciplinas isoladas que eram oferecidas como preparação para a prática clínica, hierarquizando os conhecimentos em básicos iniciais a clínico-aplicados e inserindo o estudante na prática clínica apenas nos anos finais do curso. Com forte base biomédica hospitalocêntrica, o Curso Tradicional acabava por estimular os estudantes a se voltarem à escolha de uma atuação específica e especializada desde cedo em seu ingresso, afastando-os da atenção primária, características que o CEM imprime à formação de seus estudantes.

Organizando seu currículo em busca de uma integração vertical, os conteúdos do Curso Experimental eram integrados em uma distribuição chamada de blocos que conjugavam todos os conteúdos de um sistema corporal, desde as bases até a aplicação. Propunha a antecipação da inserção dos estudantes na prática clínica, colocando-os em contato com enfermos já no terceiro ano do curso. Trazia como alinhamento conceitual a formação de um médico capaz de atendimento aos problemas gerais e mais incidentes da população, com habilidades preventivas e comunitárias, mas que também poderia optar por uma especialidade, pois contava com fundamentação e conceituação suficientes para qualquer das escolhas que o egresso fizesse, inserindo a atenção primária e secundária à formação.

Este artigo baseia-se em tese de doutorado ${ }^{1}$ apresentada à Faculdade de Educação da Universidade de São Paulo, que buscou compreender a experiência educacional sui generis que o Curso Experimental representa no campo dos estudos curriculares, valendo-se de documentos escritos, primários e secundários, bem como de documentos orais especificamente produzidos para o estudo.

\section{Protagonistas Proponentes do Curso Experimental de Medicina}

No âmbito das mudanças curriculares, é possível pensar na organização de grupos de indivíduos, que se juntariam e envolveriam na situação específica, derivando, assim, num grupamento de profissionais que compartilha a perspectiva reformadora e se envolvem na proposição de modificações, a partir da constatação de questões que devem ser ajustadas no currículo vigente. Este grupamento protagoniza as proposições de mudança a partir de suas próprias concepções de educação e formação dos estudantes, marcando-as com suas características filosofias, e têm a legitimidade conferida por seus pares a partir do atributo de conhecimento especializado. Ou seja, estes indivíduos trazem para o grupamento protagonista as suas próprias convicções, a sua própria história de consolidação de saberes e o seu território como especialistas, configurando uma proposição específica dependente do grupamento e das

1 TAVANO, Patricia Teixeira. Tramas da tessitura curricular: o Curso Experimental de Medicina da Faculdade de Medicina da Universidade de São Paulo (1968-1975). Tese de Doutorado em Educação, Faculdade de Educação, Universidade de São Paulo, São Paulo, 2015. 
contingências de formação do grupamento ${ }^{2}$.

O grupamento responsável pelo desenvolvimento da proposta do Curso Experimental de Medicina é representado por um grupo de professores da FMUSP que questionavam as possibilidades de mudança do ensino médico:

O líder desse grupo era o Professor Alípio Correa Neto (Cirurgia). O grupo pensante tinha um núcleo permanente constituído pelos professores Antônio Barros Ulhôa Cintra (Clínica Médica), Isaias Raw (Bioquímica), Alberto Carvalho da Silva (Fisiologia), Eduardo Marcondes (Pediatria) e Guilherme Rodrigues da Silva (Preventiva). (...) Havia, também, agregados permanentes, bem como interessados em educação médica que apareciam ocasionalmente [aos encontros $]^{3}$.

O núcleo permanente era formado por dois catedráticos antigos, os dois primeiros citados, com posição institucional bastante consolidada e quatro catedráticos novos na FMUSP, que assumem a cátedra durante a década de 1960.

Alípio Correa Neto é catedrático da Clínica Cirúrgica desde 1935, aposentado compulsoriamente em janeiro de 1968, após ampla produção científica e experiência como cirurgião de guerras, tendo participado da Revolução Constitucionalista de 1932 e da Força Expedicionária Brasileira na II Grande Guerra. Foi um dos fundadores da Escola Paulista de Medicina, Reitor da Universidade de São Paulo, cumpriu mandato como deputado estadual, como Secretário de Higiene da Prefeitura de São Paulo e como Secretário da Educação do Governo do Estado de São Paulo. Participou da fundação do Partido Socialista Brasileiro ${ }^{4}$ e tem ação contundente junto à Congregação da FMUSP diante da defesa de assistentes e catedráticos durante o período militar.

A ideia original do Curso Experimental é do professor Alípio, que visava um curso mais ágil, mais dinâmico, fugindo um pouco da área física do Hospital das Clínicas. ${ }^{5}$. Reconhecido pelo grupamento de propositores do Curso Experimental como figura chave, o professor não era contestado por ninguém, era respeitado e conseguia manter um diálogo e um funcionamento adequado, apesar de muita

2 LOPES, Alice Casimiro. Politicas de currículo: questões teórico-metodológicas. In: LOPES, Alice Casimiro; DIAS, Rosanne Evangelista; ABREU, Rozana Gomes de (orgs). "Discursos nas políticas de currículo". Rio de Janeiro: Quartet, Faperj, 2011. p. 19-47.

TORRES, Wagner Nóbrega; DIAS, Rosanne Evangelista. Comunidades epistêmicas nas políticas de currículo em EJA. In: LOPES, Alice Casimiro; DIAS, Rosanne Evangelista; ABREU, Rozana Gomes de (orgs). "Discursos nas políticas de currículo". Rio de Janeiro: Quartet, Faperj, 2011. p. 205-223.

3 MACHADO, Marcello Marcondes. Curso Experimental de Medicina. Acervo do Museu Histórico da FMUSP “Carlos da Silva Lacaz”. 2012. p. 1-2.

4 BEGLIOMINI, Hélio. Alípio Correa Neto. Biografias da Academia de Medicina de São Paulo. Disponível em: http://academiamedicinasaopaulo.org.br/biografias/12/BIOGRAFIA-ALIPIO-CORREANETTO.pdf. Acesso em: 10 de novembro de 2014.

RAMOS, Jairo. Alípio Correa Netto. Capitulo de São Paulo do Colégio Brasileiro de Cirurgiōes. Disponível em: http://www.cbcsp.org.br/cbc/?pagcbc=dir01. Acesso em: 10 de outubro de 2014.

MOTOYAMA, Shozo (org). USP 70 anos: imagens de uma história vivida. São Paulo: EDUSP, 2006.

LACAZ, Carlos da Silva. Curta biografia do grande cirurgião brasileiro. Disponível em: http://www.moreirajr.com.br/revistas.asp?fase=r003\&id_materia $=879$.

5 Depoimento de Eduardo Marcondes para CHASSOT, Walkíria Costa Fucilli (org). Memórias de origem: Hospital Universitário da Universidade de São Paulo 20 anos. São Paulo: Hospital Universitário - Universidade de São Paulo, 2001. p. 09. 


\section{Khronos, Revista de História da Ciência \\ ISSN 2447-2158 - no 4, agosto 2017}

oposição interna que já se sentia desde o comeşo ${ }^{6}$ do Curso. Além da experiência de sua trajetória profissional e da força coercitiva e conciliadora,

Alípio Correa Neto trouxe outra dimensão [para o CEM]. Os aspectos sociais da medicina. A integração deveria ser de imediato entre disciplina básica, clínicas e a experiência com a realidade social. Deveríamos ter um hospital pequeno, com pacientes representativos da região a que servem e com outros pacientes transferidos do Hospital das Clínicas para atender o ensino. Tão importante quanto o Hospital seria o Centro de Saúde, para que os estudantes aprendessem o atendimento da população, na maior parte das vezes com enfermidades que não exigem internação ${ }^{7}$.

Assim, a dimensão da medicina comunitária e preventiva, a atenção primária e secundária, o atendimento a enfermos não hospitalizados, são as características imprimidas por Alípio Correa Neto ao Curso Experimental, Curso que contará com outro catedrático bastante legitimado diante da comunidade médica e universitária, Ulhôa Cintra.

Antônio Barros Ulhôa Cintra assume a cadeira de Clínica Médica em 1936 e se aposenta compulsoriamente em 1978, após profícua produção científica na área médica e tendo ocupado diversas posições: foi Reitor da Universidade de São Paulo; Secretário de Educação e Cultura do Estado de São Paulo; um dos criadores e primeiro presidente da FAPESP8. Considerado o Reitor reformista da USP, em sua gestão (1960-1963) cria a Editora da Universidade de São Paulo e transfere a reitoria para a Cidade Universitária, dinamizando e expandindo o processo de ocupação do terreno da Cidade Universitária? .

Seu papel na aprovação do Curso Experimental de Medicina ultrapassa os muros da Faculdade, pois o Curso é financeiramente viabilizado em sua gestão enquanto Secretário de Educação (1967-1970) ao conduzir a proposta ao governador Abreu Sodré, [e receber] sua imediata

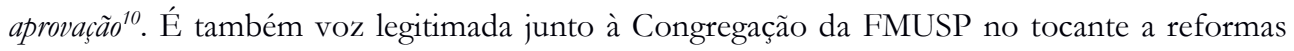
curriculares e modificações no ensino, defendendo a reforma universitária e a maior integração da Faculdade de Medicina à Universidade de São Paulo ${ }^{11}$.

Alípio Corrêa Neto e Antônio Barros Ulhôa Cintra são dois catedráticos estabelecidos não apenas junto à Faculdade de Medicina, mas junto à Universidade e ao Estado, que se so-

6 Depoimento de Guilherme Rodrigues da Silva para CHASSOT, op.cit, 2001. p. 15.

7 RAW, Isaias. Um cientista bom de briga: uma autobiografia. Acervo do Museu Histórico da FMUSP, 2012. p. 46-47.

8 MEDEIROS NETO, Geraldo. Antonio Barros de Ulhôa Cintra. Biografias da Academia de Medicina de São Paulo. Disponível em: http://www.academiamedicinasaopaulo.org.br/biografias/15/BIOGRAFIAANTONIO-BARROS-DE-ULHOA-CINTRA.pdf. Acesso em: 10 de novembro de 2014.

AZANHA, José Mario Pires. Ulhôa Cintra: estadista da educação. Revista Universidade de São Paulo, n. 42, p. 104-7, 1999. FAPESP. Memória: homenagem a Ulbôa Cintra. Revista Fapesp, n. 42, p. 6, 1999.

9 GIANNAZI, Carlos. Marcha contra o saber. o golpe militar de 1964 e o AI-5 na Universidade de São Paulo. São Paulo: Global, 2014.

MOTOYAMA, Shozo, op. cit, 2006.

ADUSP (Associação dos docentes da Universidade de São Paulo). Controle ideológico na Universidade de São Paulo: 1964-1978. São Paulo: Adusp, 2004.

AZANHA, José Mario Pires. Ulhôa Cintra: estadista da educação Revista Universidade de São Paulo, n. 42, p. 104-7, 1999.

${ }^{10}$ RAW, Isaias. Reformulação do ensino médico: Faculdade de Medicina e a USP. Revista USP. n. 20, p. 131137, 1994. p. 134b.

11 Atas da Congregação da FMUSP de 17 de abril de 1967, de 13 de maio de 1968 e de 16 de setembro de 1969. 
mam aos jovens catedráticos da FMUSP para que o Curso Experimental de Medicina ganhe espaço e consiga se cumprir. Isaias Raw, Alberto Carvalho da Silva, Guilherme Rodrigues da Silva e Eduardo Marcondes conquistam suas cátedras ao longo da década de 1960 e traçarão caminhos distintos junto ao CEM; os dois primeiros não podem acompanhar o Curso durante todo o seu período de execução, pois são cassados pelo Governo Militar.

Isaias Raw, catedrático de Bioquímica, era reconhecido por seus pares em sua liderança e desenvolvimento de ações de integração universitária: Havia um grupo de docentes liderados por Isaias Raw, que gostaria de ver uma maior integração com os vários departamentos básicos da Universidade de São Paulo e outras unidades, incluindo, a Saúde Pública ${ }^{12}$. Como parte destas ações, o professor Isaias realocou sua cátedra no ano de $1963,{ }^{13}$ do prédio da Faculdade de Medicina para o Instituto de Química na Cidade Universitária, obrigando o deslocamento dos estudantes para assistir às aulas e iniciando uma proximidade espacial da Faculdade à Cidade Universitária.

Tornar-se catedrático foi uma batalha para o professor Isaias, uma vez que o concurso foi suspenso pela reitoria com base na existência de indiciamento do professor em inquérito policial-militar em curso $^{14}$ decorrente de sua prisão em 1964. Na ocasião, Alípio Correa Neto e Ulhôa Cintra questionam a validade da ação do governo em um concurso interno à Faculdade e exigem posicionamento da direção junto ao Conselho Universitário ${ }^{15}$. O professor Isaias é mantido interinamente na cátedra e posteriormente o concurso é autorizado, conquistando a cátedra oficialmente para ser aposentado compulsoriamente por decreto federal, em 30 de abril de $1969^{16}$.

Vale notar que o caso de Isaias Raw é bastante discutido e questionado em bases de ilegalidade, vingança e demonstração de poder ${ }^{17}$. O professor era considerado candidato imbatível à seleção para a cátedra de Bioquímica e, mesmo sendo bastante jovem, já trazia em sua história junto à Faculdade de Medicina, desde estudante, uma série de bolsas de estudos no exterior, participações em Congressos Internacionais e respeitabilidade internacional de tal monta que, por ocasião de sua prisão em 1964, a comunidade internacional se mobiliza e exige, junto ao Governo brasileiro, sua libertação. Desde 1952, então com 25 anos, era preocupado com a reforma do ensino de ciências, propondo a utilização de coisas do cotidiano para ensinar ciências e a necessidade da experimentação para o aprendizado. O professor é figura conhecida e pública e o seu trabalho junto ao IBECC (Instituto Brasileiro de Educação, Ciência e Cultura) terá papel central na dinamização nas atividades de divulgação cientifica do IBECC/SP, assumindo uma liderança carismática engajada numa proposta inovadora de ensino de ciências, com participação ativa nos projetos de exibições cientificas, clubes de ciências, programas de televisão, feiras de ciências, concursos científicos e produção de kits de ciências ${ }^{18}$, tornando-o figura obrigatória em todos os debates sobre o ensino ${ }^{19}$. A soma destes elementos teria ferido algumas susceptibilidades e causado enorme resistência à sua ascensão na Faculdade de Medicina, tão ciosa de suas posições consolidadas e convencionais.

\footnotetext{
12 Depoimento de Guilherme Rodrigues da Silva para CHASSOT, op.cit, 2001. p. 15.

13 RAW, op. cit, 2012.

14 Ata da Congregação da FMUSP de 13 de outubro de 1964, volume 7, p. 46v.

15 Ata da Congregação da FMUSP de 13 de outubro de 1964, volume 7, p. 45-51v.

16 Ata da Congregação da FMUSP de 13 de maio de 1969, volume 8, p. 04.

17 GIANNAZI, op. Cit., 2014.

ABRANTES, Antônio Carlos Souza de. Ciência, educação e sociedade: o caso do Instituto Brasileiro de Educação, Ciência e Cultura (IBECC) e da Fundação Brasileira de Ensino de Ciências (FUNBEC). Tese de Doutorado em História das Ciências e da Saúde, Fundação Oswaldo Cruz. Casa de Oswaldo Cruz, 2008.

ADUSP, op. Cit., 2004.

18 ABRANTES, op. cit, 2008. p. 148.

19 ADUSP, op. cit, 2004. p. 58.
} 
Alberto Carvalho da Silva também se defrontou com problemas para assumir a cátedra de Fisiologia em 1964, enfrentando um recurso de nulidade impetrado que teve de ser derrubado pela votação em Congregação e que novamente contou com a intervenção de Alípio Correa Neto e Ulhôa Cintra ${ }^{20}$. O professor participou da fundação e foi diretor científico da FAPESP, exercendo poderosa influência em prol da pesquisa cientificica ${ }^{21}$. Ao lado de professor Isaias, Alberto Carvalho foi aposentado compulsoriamente por decreto federal em 30 de abril de 196922 .

Isaias Raw ${ }^{23}$ e Alberto Carvalho da Silva ${ }^{24}$, em mandatos sequenciais, representarão a Faculdade de Medicina junto ao CESCEM (Centro de Seleção dos Candidatos às Escolas Médicas de São Paulo), uma forma de seleção integrada para todas as faculdades de medicina do Estado de São Paulo, que permitia ao candidato, em um único vestibular, colocar a ordem de preferência das faculdades e conquistar uma vaga conforme sua classificação nesta seleção, reforçando, assim o comprometimento com as mudanças no ensino médico. Eles expressam participação contundente junto à Congregação da FMUSP na defesa da reforma do ensino na Faculdade de Medicina ${ }^{25}$ mantendo, algumas vezes, uma unidade de ação e declarações, incluindo a verbalização de apoio recíproco ${ }^{26}$. Vale ainda notar que os professores Isaias e Alberto são os únicos - ao lado de Reinaldo Chiaverini, que também foi cassado por decreto federal, em 30 de abril de $1969^{27}$ - a se recusarem a assinar a moção de apoio da FMUSP à tomada do poder pelos militares em abril de $1964^{28}$.

A aposentadoria de Isaias Raw e de Alberto Carvalho da Silva é menos creditada a fatores políticos e mais a desavenças que os dois teriam junto à Faculdade de Medicina:

Alberto Carvalho da Silva foi um dos cassados (...) então não pôde participar tanto assim, era meio difícil trazer ele pra participar. Aquela época era complicado. Embora a cassação dele até hoje eu não entendi bem o por quê. Porque não tem nada, não era subversivo, porque acho que ele protegeu algum professor da Faculdade de Medicina, um desses que hoje tá, que ficou lá nos Estados Unidos, se radicou nos Estados Unidos, que pra como era comunista não servia pro Brasil, mas foi morar nos Estados Unidos $!^{29} \mathrm{O}$ Isaias Raw foi demitido sumariamente. O Eduardo Marcondes não. O Isaias Raw foi por bobagem. Nunca foi político, nunca foi. Comunista então nem se fala! Ele tinha uma briga dentro da Faculdade de Medicina ${ }^{30}$.

Situação que pode se vislumbrar pela trajetória que ambos descrevem, de posicionamentos reformistas e progressistas, e que muitas das vezes contrapunham-se ao alinhamento mais convencionalista que a FMUSP expressava. Assim, quando foi possível à Faculdade,

\footnotetext{
20 Ata da Congregação da FMUSP de 08 de abril de 1964, volume 7, p. 24v-25.

21 ADUSP, op. Cit, 2004. p. 58.

22 Ata da Congregação da FMUSP de 13 de maio de 1969, volume 8, p. 04.

23 Ata da Congregação da FMUSP de 06 de agosto de 1963, volume 6, p. 296-297.

24 Ata da Congregação da FMUSP de 27 de outubro de 1967, volume 7, p. 212.

25 Ata da Congregação da FMUSP de 05 de novembro de 1965.

26 Ata da Congregação da FMUSP de 22 de junho de 1965 e de 13 de maio de 1968.

27 Ata da Congregação da FMUSP de 13 de maio de 1969, volume 8, p. 04.

28 Ata da Congregação da FMUSP de 03 de abril de 1964, p. 22v-23.

29 Depoimento de antigo estudante da $1^{a}$ turma do CEM para TAVANO, op. cit, 2015.

30 Depoimento de antigo professor de Farmacologia do CEM TAVANO, op. cit, 2015.
} 
quando a Faculdade encontrou uma via legal de afastar dois professores que causavam tensão em uma zona de conforto construída ao longo das décadas, não houve hesitação ${ }^{31}$.

Do núcleo duro inicial, composto por Alípio Corrêa Neto, Antônio de Barros Ulhôa Cintra, Isaias Raw, Alberto Carvalho da Silva, Eduardo Marcondes e Guilherme Rodrigues da Silva, estes dois últimos acompanharão cotidianamente o Curso Experimental de Medicina. O primeiro na posição de Coordenador Geral, o segundo como coordenador da área de Medicina Preventiva.

Guilherme Rodrigues da Silva assume a posição de catedrático em 196732 , na cátedra de Higiene e Medicina Preventiva criada dois anos antes ${ }^{33}$ e vindo de uma formação médica na Faculdade de Medicina da Bahia, com doutoramento pela Harvard University ${ }^{34}$

Ele era um professor que não era formado na casa, o que já significava alguns problemas. Esta casa tem um certo, digamos, repúdio, aos professores que não eram formados aqui na casa; hoje em dia se você auscultar os estudantes, alguns acham que é isso mesmo: os residentes têm que ser os estudantes da casa, as vagas têm que ser garantidas, enfim, houve várias coisas tenebrosas e preconceituosas que não vem ao caso aqui mas o professor Guilherme rapidamente ao chegar aqui tomou uma posição de liderança importante na discussão, no debate. Ainda que, não sei se marginalizado é o termo, mas não tendo oportunidade de ocupar os espaços que eu acho que ele seria bastante competente direção da escola, direção de comissões, essa coisa toda nunca lhe foi oferecido, mas ele sempre foi uma voz EXTREMAMENTE importante em todos os debates, todas as questões que tinham respeito à reforma de currículo, era uma pessoa atualizada que conhecia o que estava acontecendo e se engajou bastante nesse processo. E também ele teve uma participação importante na reforma sanitária brasileira, era uma liderança reconhecida do ponto de vista político, do ponto de vista social, o que lhe deu então possibilidade de estar conduzindo, se envolver nesse processo todo do curso experimental, teve um papel extremamente importante na concepção do Hospital Universitário, trazendo ideias de fora, ele foi importante na concepção do centro de saúde-escola e na discussão dos rumos do curso experimental. Sem dúvida 35 .

O professor Guilherme é, então, excluído, preterido em diversas situações em que poderia trazer contribuições significativas, por ser um forasteiro na Faculdade de Medicina. Além disso, vinculado a uma área médica de baixo prestígio, a Medicina Preventiva ${ }^{36}$, e associado aos

31 É de extremada importância que fique registrado que Isaias Raw e Alberto Carvalho da Silva não são os únicos professores afastados na FMUSP, tampouco da USP. Entretanto, são os dois diretamente vinculados ao grupamento de propositores do Curso Experimental de Medicina, objeto deste artigo. Para a listagem completa de professores consultar o decreto-lei de 30 de abril de 1969, do Ministério da Educação e Cultura.

32 Ata da Congregação da FMUSP de 25 de agosto de 1967, volume 7, p. 182.

33 Ata da Congregação da FMUSP de 09 de abril de 1965, volume 7, p. 90.

34 AYRES, José Ricardo de Carvalho Mesquita; MOTA, André. Medicina Preventiva. In: MOTA, André; MARINHO, Maria Gabriela S. M. C. (orgs). "Trajetória da Faculdade de Medicina da Universidade de São Paulo: aspectos históricos da Casa de Arnaldo". Departamentos da Faculdade de Medicina da Universidade de São Paulo: Memórias e Histórias. São Paulo: FMUSP, 2012. p. 124-137. (volume 2).

35 Depoimento de antigo professor de Medicina Preventiva do CEM para TAVANO, op. cit, 2015.

36 MARCONDES, Eduardo. O curso experimental de medicina da Universidade de São Paulo. Educación médica y salud. v. 9, n. 2, p. 172-195. 1975. 
movimentos políticos de esquerda: Guilherme Rodrigues da Silva, [era] complicado, minucioso e segurava muito os processos (...) era um dos líderes da esquerda ${ }^{37}$.

E ser um dos líderes da esquerda também coloca o professor sob suspeição do Governo Militar, para além da resistência da própria Faculdade de Medicina:

Alguns professores que sofreram. Guilherme Rodrigues foi um deles, que era da Medicina Preventiva. Tinha um outro, o Euclydes que também era da Medicina Preventiva ... esse pessoal que tinha uma atividade mais, vamos dizer, social, eles [refere-se a agentes da ditadura] ficaram de olho bem perto deles. Eles realmente foram perseguidos. O Guilherme era uma situação meio estranha porque ele era baiano, preto, professor titular e ele era abertamente comunista. Então tinha tudo negativo pra ditadura ir atrás dele! Então ele foi um cara que foi meio perseguido ${ }^{38}$.

Eduardo Marcondes assume a cátedra interinamente após aposentadoria do pai, Pedro de Alcântara Marcondes Machado ${ }^{39}$, e será aprovado no concurso em 1966 ${ }^{40}$, enfrentando resistências:

E o professor Marcondes, embora ele tivesse interesse no social, não era uma pessoa de esquerda. De jeito nenhum. Ele era filho do grande Pedro de Alcântara, então ele estava muito bem escudado nos catedráticos. Claro que várias pessoas, outros professores da pediatria tinham raiva do Eduardo Marcondes porque diziam que ele tinha ganho a cátedra porque ele era filho do Pedro de Alcântara - que foi o grande professor de pediatria dos anos 40, 50 e tinha sido uma pessoa muito importante - e alguns deles eu acredito, aproveitaram esse momento mais obscuro da história, juntando com a raiva que tinham, e deram um jeito de bloquear as propostas mais pra frente do professor e colocar o professor mais pra escanteio. Mas ele de jeito nenhum era uma pessoa de esquerda. Era uma pessoa assim, interessada numa reforma pedagógica, numa modernização. Ele gostava bastante da pediatria social, mas naquela época a pediatria TODA tinha esse caráter menos patológico e mais digamos social, porque as crianças eram vistas pelos pediatras para o bom desenvolvimento, de prevenção e de promoção da saúde, não porque tinham muitas patologias. Hoje em dia que a pediatria é também uma área que tem também muitos especialistas em patologias. Mas antes não tinha ${ }^{41}$.

Eduardo Marcondes tem de superar as resistências à sua posição conquistada por concurso e desenvolve trajetória na Faculdade de Medicina junto às reformas curriculares. Defensor de uma formação médica que permitisse o desenvolvimento de médicos preparados para atuar nos hospitais, mas também oportunizasse a atuação na comunidade ${ }^{42}$, o professor não era unanimidade na Faculdade nem à época de seu concurso para cátedra, nem ao longo de sua carreira:

\footnotetext{
37 Depoimento de Sebastião de Almeida Prado Sampaio para CHASSOT, op cit, 2001.p. 22.

38 Depoimento de antigo estudante da $1^{\mathrm{a}}$ turma do CEM para TAVANO, op. cit, 2015.

39 Ata da Congregação da FMUSP de 10 de agosto de 1964, volume 7, p. 42.

40 Ata da Congregação da FMUSP de 02 de fevereiro de 1966, volume 7, p. 131.

41 Depoimento de antigo professor de Medicina Preventiva do CEM para TAVANO, op. cit, 2015.

42 MARCONDES, op. cit. 1975.
} 
O professor Eduardo Marcondes ouvia e pouco argumentava. Eu, pelo contrário, procurava impor minha visão, e, geralmente, tinha apoio. A minha impressão do professor Eduardo Marcondes é de uma pessoa que está sempre inventando problemas, para procurar soluções. Complicava fatos simples para torná-los difíceis. Estava sempre propondo mudanças no currículo médico que malogravam. É o caso do Curso Experimental de Medicina que acabou sendo extinto. O professor Eduardo não tinha clínica, fazia tempo integral na Faculdade, e inventava reformas ${ }^{43}$.

Este grupamento de professores propositores do Curso Experimental descreve trajetórias diferenciadas e marcadas por uma sucessão de atividades voltadas para a compreensão da educação médica, a partir de outras bases que não a convencional formação técnicoinstrumental, mais usual nos professores de medicina. Um grupo formado por indivíduos com percurso profissional e pessoal que aponta para a mudança, para uma compreensão do processo formativo pouco diferenciada da que decorria na Faculdade de Medicina.

Entretanto, o afastamento da situação de ensino tradicional não era um afastamento da tradição da Faculdade de Medicina: Nos anos 60, para nós, que construímos o curso experimental, o desafio de inovar o ensino médico era parte do orgulho de pertencer " $A$ " Faculdade de Medicina, ao invés de dormir no berço esplêndido que o padrão $A$ da $A M A^{44}$ representou. ${ }^{45}$

O grupo de propositores do Curso Experimental de Medicina não estava negando a Faculdade de Medicina e sim buscando a retomada de uma posição de vanguarda que é incutida na construção social da Faculdade, desde sua origem, quando Arnaldo Vieira de Carvalho determina que a Faculdade de Medicina tivesse um ensino aliado à pesquisa laboratorial, afastando-se do ensino enciclopédico das congêneres da década de 191046; posição que o grupo acredita que a Faculdade não está ocupando ao se manter alheia às novas tendências educacionais contemporâneas e se manter fixada ao seu tradicional modus operandi de formação médica, que sim, guarda a construção iniciada por Arnaldo Vieira, mas que já não se mostraria tão atual quanto Dr. Arnaldo buscou imprimir em sua gestão. Logo, o grupamento de propositores fundamentava-se na mais antiga tradição da Faculdade de Medicina, a auto-alcunhada "Casa de Arnaldo": cumprir com os desejos de seu primeiro diretor-fundador de se manter na vanguarda educacional.

III. Contingências sócio-históricas para implementação do Curso Experimental de Medicina

Destarte, o Curso Experimental é oferecido quando a Faculdade de Medicina - e o seu curso médico oferecido desde 1913 - ocupava posição de destaque diante da comunidade médica nacional e internacional: seja como formadora de profissionais de qualidade; seja como curadora de inovações no tratamento e atendimento de doenças e disfunções, como o desenvolvimento de técnicas cirúrgicas e de transplante de órgãos; seja como provedora de decisões

43 Depoimento de Sebastião de Almeida Prado Sampaio para CHASSOT, op. cit, 2001. p. 23.

44 No ano de 1951, a FMUSP é considerada pela American Medical Association uma das 50 instituições mundiais com ensino médico compatível às melhores instituições norte-americanas. Para mais informações, consultar AMERICAN MEDICAL ASSOCIATION, fax-símile do comunicado do secretário da Associação. 13 de março de 1951. Acervo do Museu Histórico da FMUSP "Carlos da Silva Lacaz".

45 RAW, op. cit, 1994.p. 135b.

46 TAVANO, Patricia Teixeira. Onde a morte se compraz em auxiliar a vida: a trajetória da disciplina de Anatomia Humana no currículo médico da primeira Faculdade oficial de Medicina de São Paulo. O período de Renato Locchi (1937-1955). Dissertação de Mestrado, Faculdade de Educação, apresentada à USP, São Paulo, 2011. 
em saúde e educação pública, através do fornecimento de quadros para a administração municipal, estadual e federal. E, apesar de integrar a Universidade de São Paulo há mais de 30 anos, a Faculdade de Medicina ainda mantinha sua privilegiada sede exclusiva e autossuficiente, que contava com a conexão física entre laboratórios de pesquisa, salas de aula e prática clínicahospitalar, prática esta em potencial expansão com o alargamento das atividades e prédios de especialidade do Hospital das Clínicas, mas sem se integrar fisicamente à Cidade Universitária ${ }^{47}$.

Este grupamento de propositores emerge desse contexto, pois - exceto Guilherme Rodrigues da Silva - todos eram antigos alunos da Faculdade de Medicina e, por isso, conheciam bastante bem as tradições às quais foram aculturados. Somando às disposições pessoais e conjuntas pelas reformas, amalgamam-se e aproveitam o espaço-tempo de agitações sociais, culturais, políticas, econômicas, educacionais para dar vazão à proposta reformista, conseguindo com que, ao final de 1966, o Curso Experimental de Medicina recebesse o parecer favorável à sua implementação da Congregação da Faculdade de Medicina ${ }^{48}$. O parecer indica que o curso atenderia à sugestão da reitoria de aumento de vagas e conclui pela viabilidade da criação do novo curso com aumento de 50 vagas, mas isso não seria possível em 1967, apenas em $1968^{49}$.

A pressão pela expansão na oferta de vagas para os cursos superiores não é exclusivo sobre a Faculdade de Medicina e nem pontual. É um problema que se mostra desde a década de 1950 e que atinge o sistema educacional tanto no Brasil, quanto na Europa ${ }^{50}$, sendo conhecida como "crise dos excedentes".

Luiz Antônio Cunha indica que a procura pelo ensino superior se intensifica na década de 1960, ainda que já se mostrasse numa crescente busca desde a década de 1940, por conta do crescimento da população urbana, a industrialização e a monopolização, gerando aumento das camadas médias, em termos absolutos, a redefinição do papel da mulher como trabalhadora no âmbito extra-doméstico, a elevação dos requisitos educacionais para o preenchimento dos cargos nas burocracias públicas e privadas ${ }^{51}$.

O aumento da procura aliava-se a uma legislação dúbia de seleção, que determinava que estivessem aprovados nos vestibulares os candidatos com nota igual ou superior a cinco, instituindo um contingente de candidatos aprovados que não conseguem se matricular mesmo tendo alcançado a nota determinada, pois, não há quantidade de vagas disponíveis nas faculdades brasileiras, ou seja, cria-se um grupo de aprovados "excedentes" que ficam de fora da educação superior mesmo que tenham atributos legais para conquistar a vaga. Como resultado, os cursos superiores tinham pendências jurídicas com mandatos de segurança impetrados por candidatos excedentes, o que era mais expressivo nos cursos de Engenharia e Medicina, também porque eram os mais concorridos ${ }^{52}$.

\footnotetext{
47 TAVANO, op. cit, 2011.

MARINHO, Maria Gabriela S. M. C. Trajetória da Faculdade de Medicina da Universidade de São Paulo: aspectos históricos da "Casa de Arnaldo". São Paulo: FMUSP, 2006.

MOTA, André. Tropeços da medicina bandeirante: medicina paulista entre 1892-1920. São Paulo: EDUSP, 2005 SILVA, Márcia Regina Barros da. O mundo transformado em laboratório: ensino médico e produção do conbecimento em São Paulo de 1891 a 1933. Tese de Doutorado, Faculdade de Filosofia, Letras e Ciências Humanas, apresentada à USP, São Paulo, 2003.

NADAI, Elza. Ideologia do progresso e do ensino superior. São Paulo 1891-1934. São Paulo: Loyola, 1987.

48 Ata da Congregação da FMUSP de 17 de novembro de 1966, volume 7, p. 161v.

49 Ata da Congregação da FMUSP de 16 de dezembro de 1966, volume 7, p. 165-166.

50 BRAGHINI, Katya Mitzuko Zuquim. A história dos estudantes "excedentes" nos anos 1960: a superlotação das universidades e um "torvelinho de situações improvisadas". Educar em Revista. N. 51, p. 123-144. 2014.

51 CUNHA, Luiz Antônio. A universidade reformanda: o golpe de 1964 e a modernização do ensino superior. 2 ed. São Paulo: Unesp, 2007b. p. 81.

52 CUNHA, op.cit, 2007b. p. 83.
} 
Por conta desta pressão, a Faculdade de Medicina da Universidade de São Paulo ofereceu mais 20 vagas a partir de 1962, completando 100 vagas para seu curso médico ${ }^{53}$. Contudo, a pressão governamental não cessa e anualmente a discussão sobre a possibilidade de maior expansão é retomada, sempre sendo negada.

No início de 1964, o tema toma novos contornos, com a promulgação de um decreto presidencial que propunha a duplicação do número de vagas para o primeiro ano dos cursos superiores nos setores de Medicina, Engenharia, Química, Odontologia e Geologia ${ }^{54}$. Este decreto tentava responder à pressão popular pela solução do problema dos jovens que não podiam chegar aos cursos superiores, pauta recorrente nos movimentos estudantis do período, mas que também se fundamentava no crescimento do país e na necessidade de profissionais qualificados para suprir a demanda expansionista, o que previa o subsídio do Governo Federal para a expansão e disponibilização de recursos físicos do Ministério da Saúde para os cursos de medicina. A Faculdade de Medicina da USP recusa a expansão mas, pouco depois, o Governo Militar se instala e toma o acesso ao ensino superior como uma forma de recompensar as camadas médias que tão valioso apoio político dera ao golpe de Estado" e logo "o MEC passou a induzir as universidades federais a aumentarem as vagas, principalmente nas grandes cidades e nos cursos de Medicina e Engenharia $a^{55}$.

A pressão não se restringe às universidades federais, é sentida na FMUSP através das solicitações da reitoria ${ }^{56}$ e é uma das causas apontadas para, ao final de 1966, a Congregação decidir pela aprovação do Curso Experimental de Medicina como forma de ampliação de vagas. Contudo, como essa ampliação viria apenas em 1968, o ano de 1967 segue com as discussões pela ampliação imediata das vagas ${ }^{57}$. É, então, resgatada uma tradição fundante da Faculdade de Medicina para rechaçar a ampliação:

O numerus clausus, a frequência obrigatória, o tempo integral, a distribuição didática em departamentos compõem um todo uno e indiviso e a renúncia a quaisquer desses componentes redundaria em prejuízo total ao sistema. A nossa Faculdade tem por obrigação formar médicos de boa qualidade, mantendo também a investigação científica no mesmo nível em que se faz o ensino ${ }^{58}$.

Com esta retumbante recordação da tradição da Escola, recorrendo aos acordos da década de 1920 com a Fundação Rockefeller, a discussão é encerrada e não se altera o número de ingressantes em 1967. A quantidade total de vagas oferecidas pela FMUSP apenas seria alterada com a criação de um novo curso médico, o Curso Experimental de Medicina, garantindo assim que o proclamado "todo uno e indiviso" fosse mantido, já que não se alteraria o numerus clausus diretamente, pois o Curso Tradicional preservaria suas características.

Contudo, quando a estruturação do Curso Experimental é colocada em pauta na Congregação da Faculdade de Medicina, a criação deste curso é questionada nas bases da necessidade de expansão das vagas que se propôs:

\footnotetext{
53 Atas da Congregação da FMUSP de 14 de dezembro de 1960, p. 131 e de 11 de dezembro de 1961, p. 198-200.

54 Decreto $n^{\circ}$ 53.642, de 28 de Fevereiro de 1964. Dispõe sobre a duplicação de matrículas no primeiro ano das escolas superiores.

55 CUNHA, op.cit, 2007b., p. 82.

56 Cf., por exemplo, Ata da Congregação de 17 de novembro de 1966, p. 161.

57 Ata da Congregação da FMUSP de 10 de janeiro de 1967, p. 170.

58 Ata da Congregação da FMUSP de 17 de abril de 1967, p. 185.
} 
O prof. Junqueira indaga se é necessário criar o Curso Experimental na Cidade Universitária em vista da pletora de Faculdades de Medicina que ora estão criando. Acredita que este assunto de aumento de vagas já está superado. O prof. Alberto Carvalho da Silva dá os seguintes dados: existem realmente 750 vagas com perspectivas de aumento de 850, 950 para o ano que vem [1968], para uma população de 15 milhões de habitantes. Portanto, não há de fato, no momento necessidade de um aumento no $\mathrm{n}^{\circ}$ de vagas. A população média do Estado gira em torno de 13.000 médicos, pelas últimas estatísticas do CREMESP e creio que não há de fato necessidade urgente de um aumento do número de vagas. A incumbência que recebi do senhor Diretor para integrar a comissão tem como finalidade a formação do novo curso experimental, a fim de testarmos nova modalidade de ensino médico, novas técnicas e fornecer maior número de vagas, a fim de atender solicitação do governo e da sociedade. A minha opinião sobre o aumento do $\mathrm{n}^{\circ}$ de vagas, do ponto de vista das necessidades reais do Estado não devem ser consideradas como aspecto importante da discussão. O relatório da Comissão, se for aprovado e posto em prática, virá dar oportunidade de testar novos métodos de ensino e dar ensejo à Faculdade de Medicina de contribuir e estimular o desenvolvimento da Cidade Universitária. ${ }^{59}$

Ou seja, Alberto Carvalho da Silva, um dos propositores do Curso Experimental, concorda que não há necessidade de expansão de vagas nos cursos médicos no Estado de São Paulo, porém indica para outros benefícios da criação deste curso. A contenda por mais vagas nos cursos superiores está de fato imbricada na criação do Curso Experimental, mas não pode ser considerada como o motor para a criação do novo curso; mais se aproxima a um pretexto contingencial, onde os propositores aproveitaram a pressão da "crise dos excedentes" para introduzir uma ideia que tiraria das costas da Faculdade de Medicina essa pressão, sem comprometer o lugar ocupado pelo curso convencional, como indica professor Isaias Raw: Son favorável a um número de vagas adequado ao mercado, pois a pressão popular é grande (...) a minha motivação não é pelo aumento do número de vagas, simplesmente, mas sim aproveitar o ambiente oficial favorável para obter recursos e realizar um curso novo que melhore o ensino médico na Universidade de São Paulo $0^{60}$.

Assim, o pretexto do aumento das vagas é claro para os propositores, que buscam, em complementariedade, a integração da Faculdade de Medicina à Cidade Universitária e repensar o ensino médico atualizando-o, tal como sintetiza professor Eduardo Marcondes: o projeto de criação de um curso experimental tem 3 motivacões: $1^{\circ}$ terço: aumento do $n^{\circ}$ de vagas (...) $2^{\circ}$ terço é tentar um curso diferente que não sabemos se vai ser melhor ou pior (...) $3^{\circ}$ terço é ir para o "campus" da Cidade Universitária ${ }^{61}$.

Portanto, a crise dos excedentes é real e incômoda e também bastante oportuna para que uma das aspirações de Ulhôa Cintra fosse cumprida, a tomada da Cidade Universitária pela Faculdade de Medicina.

Ainda que a Cidade Universitária "Armando de Salles Oliveira" seja uma idealização da década de 1940, é na gestão de Ulhôa Cintra como reitor que a sua expansão é retomada e os

59 Ata da Congregação da FMUSP de 11 de julho de 1967, p. 194v.

60 Ata da Congregação da FMUSP de 11 de julho de 1967, p. 195.

61 Ata da Congregação da FMUSP de 11 de julho de 1967, p. 196v-197. 
institutos da Universidade de São Paulo vão se transferindo ou instalando neste novo espaço ${ }^{62}$. Em 1961, o aparato administrativo da reitoria se instala no novo campus e a expansão se acelera com a construção de laboratórios, prédio e infra-estrutura para acomodar os institutos ${ }^{63}$.

No processo de expansão e ocupação da Cidade Universitária, no ano de 1962, Ulhôa Cintra fala à Congregação da Faculdade de Medicina, exortando-a a participar mais ativamente: A participação da Faculdade de Medicina nos Institutos Universitários em fase de criação não implica em alteração da atual estrutura desta Faculdade (...) é medida que se impõe, em vista da possibilidade de ser criada, no futuro, uma nova Faculdade de Medicina na Cidade Universitária. Não deve a nossa Escola omitir-se em assunto de tanto interesse ${ }^{64}$. Contudo, até o início das atividades do Curso Experimental, a única relação da Faculdade de Medicina com a Cidade Universitária era a cátedra de Bioquímica no prédio das Químicas na Cidade Universitária.

Em 1967, Alípio Correa Neto retomará a preocupação de Ulhôa Cintra de criação de outro curso de medicina: nós devemos urgentemente integrar a Faculdade de Medicina no "campus" universitário antes que outros o façam, e este é o momento ideal a pedido do próprio governo que solicita insistentemen$t e^{65}$.

Havia urgência de aumentar a influência da Faculdade de Medicina junto à Universidade de São Paulo, indica o professor Alípio, pois tramitava junto ao Conselho Universitário da Universidade de São Paulo uma solicitação de abertura de um novo curso médico na Faculdade de Odontologia de Bauru, que contava com a simpatia de muitos dos conselheiros ${ }^{66}$, o que reduziria a destinação de verbas para a Faculdade de Medicina e poderia estimular, por exemplo, a Faculdade de Odontologia, instalada na Cidade Universitária, a também propor um curso médico. Mas é possível que houvesse também outra urgência. Ulhôa Cintra ocupava, então, o cargo de Secretário de Educação e Cultura do Estado de São Paulo e estava em posição de influenciar a liberação necessária de verbas para que a ocupação pudesse ser efetivada, além do fato da realização pessoal que o ex-reitor teria, tendo satisfeita sua posição clara e contundente sobre a integração:

A formação universitária deve visar o atendimento dos interesses da coletividade, e não pode se ater aos isolacionismos formativos. A vida em comum, de estudantes de ciências, de tecnologia e de humanidades, deverá conduzir a verdadeiras transfusões de conhecimentos. O diálogo entre cientistas e humanistas no ensino superior trará imensos frutos, se enraizar-se em ações integradas, isto é, nos projetos e trabalhos elaborados e realizados em comum, por estudantes e especialistas de diferentes disciplinas. O diálogo entre o engenheiro, o médico, o economista, o sociólogo, o psicólogo, o administrador, será incontestavelmente ponto de partida de um processo educativo próprio, de forma a desenvolver em cada um, as aptidões do trabalho em comum, assim como a compreensão da tarefa, da função e do respeito aos demais. O contato individual e social, entre professores e estudantes das diversas faculdades, forçosamente determinará a valorização dos homens de valor e o seu aproveitamento em benefício da coletividade universitária, permitindo que se elimine, inclusive, um dos graves inconvenientes atualmente existentes,

\footnotetext{
62 BARROS, Lídia Almeida. Toponímia oficial e espontânea na Cidade Universitária. Campus Butantã da Universidade de São Paulo. Revista Universidade de São Paulo. N. 56, p. 164-171, 2003.

63 MOTOYAMA, Shozo, op. cit, 2006.

64 Ata da Congregação da FMUSP de 04 de julho de 1962, p. 214-215.

65 Ata da Congregação da FMUSP de 11 de julho de 1967, p. 196.

66 Ata da Congregação da FMUSP de 27 de dezembro de 1967, p. 219v.
} 
ou seja, a completa falta de contato entre os professores entre si, entre os professores e estudantes e entre eles, o que inclusive vem motivando uma série de incompreensões nos meios universitários ${ }^{67}$.

Exortando à ocupação de espaços coletivos, ao estabelecimento de cooperações entre diferentes áreas, não apenas como forma de produção mas como forma de respeito e reconhecimento das potencialidades do outro, é assim que o antigo reitor enxergava a necessária e inadiável integração. Entretanto, a conquista da sede própria foi uma luta pessoal de Arnaldo Vieira de Carvalho, que se sentia desagradado com a dispersão dos professores e estudantes em diversos espaços na cidade de São Paulo, reduzindo o poder de aculturação que a Faculdade de Medicina poderia ter se os abrigasse a todos em um espaço de compartilhamento único. ${ }^{68}$ Portanto, deixar a "Casa de Arnaldo" não era uma opção viável, nem mesmo para satisfazer um dos nomes mais ilustres da "Casa", pois deixá-la, mesmo parcialmente, seria trair a tradição e o nome de Dr. Arnaldo. Portanto, era necessário encontrar outra solução para satisfazer Ulhôa Cintra e a solução se deu na aprova a criação do CEM usando o espaço da Cidade Universitária. Com isso, a tradição da "Casa de Arnaldo" íntegra é mantida, mas a Cidade Universitária é ocupada, ainda que apenas por seu experimento.

Não se pode deixar de pontuar que a ocupação da Cidade Universitária podia ser entendida como um rebaixamento, visto que ainda é usual a forma de professores e estudantes se referirem à Faculdade de Medicina como "em cima” e à Cidade Universitária como "embaixo". Em primeiro momento, a alusão é dada pela posição geográfica na cidade de São Paulo, onde o prédio da Faculdade de Medicina estando localizado em uma zona mais alta da cidade, seria referido como em cima, na contrapartida da Cidade Universitária, posicionada na linha da várzea do Rio Pinheiros, referido como embaixo. Contudo, a referência não é apenas geográfica, mas transveste-se de pejoração ao incutir um grau de inferioridade à Cidade Universitária:

Os estudantes reclamam do primeiro e do segundo ano que eles passam muito na Cidade Universitária, e o sonho deles é aqui. Aqui é a faculdade de medicina, né! Eu sei que lá, aquilo é uma coisa muito distante pra eles. Lá também eles se sentem, sem dúvida, sem dúvida eles se sentem [menos médicos]. E o pessoal lá, muitos são médicos mas eles dificilmente tem uma coisa da integração dos anos básicos com o resto, de ligar um pouco com a doença, com a clínica, com a medicina. Mas é uma queixa. E a distância! Ele tem que ir até LÁ, aqui é mais CENTRAL, a Cidade Universitária É LINDA mas AQUI é a CASA deles! Aqui é o meu habitat, eu quando vou pro $\mathrm{HU}$, eu não consigo estacionar o carro, pouca gente me conhece, eu pego trânsito! ${ }^{69}$

Ir para a Cidade Universitária é se deslocar do centro para a periferia, é sair do lugar de destaque conquistado pela Faculdade de Medicina e se rebaixar, se misturando a outros cursos, perdendo parte do status e poder associado ao lugar que o prédio da Faculdade de Medicina ocupa nos imaginários. E esta perda não é facilmente suportada, contudo, é preciso acolher a força de Ulhôa Cintra. A criação de um curso diferente, que não compromete a tradição for-

${ }^{67}$ UNIVERSIDADE DE SÃO PAULO. Fundo para a construção da Cidade Universitária "Armando Salles de Oliveira". Relatório Geral 1959-1963. Mimeo. 1963, p. IX-X.

68 TAVANO, Patricia Teixeira. Onde a morte se compraz em auxiliar a vida: A trajetória da disciplina de Anatomia Humana no curriculo médico da primeira Faculdade oficial de Medicina de São Paulo. O período de Renato Locchi (1937-1955). Dissertação de Mestrado, Faculdade de Educação, apresentada à USP, São Paulo, 2011.

69 Depoimento de antigo estudante do Curso Tradicional de Medicina para TAVANO, op. cit, 2015. 
madora tampouco o lugar ocupado, e quiçá se reverta em um trunfo no reforço da tradição inovadora e vanguardista da Faculdade, no melhor estilo de Arnaldo Vieira de Carvalho, parece ser uma decisão acertada. É preciso ir "lá para baixo", mas sem perder o status "lá de cima". É preciso formar mais médicos e reforçar a posição de destaque da FMUSP, mas sem abrir mão da tradição. Mas é preciso, também, acompanhar as mudanças no ensino médico que estão ocorrendo pelo mundo e manter a posição de pináculo da formação médica paulista.

Maria Regina Guimarães ${ }^{70}$ sinaliza que, até a década de 1950 , a preocupação do ensino médico voltava-se essencialmente às instalações e ao melhor preparo [técnico] dos professores. Questões como os métodos de ensino e a coordenação das atividades didáticas das cátedras não compunham as discussões sobre educação médica. Entretanto, as décadas de 1950 e 1960 trazem essa discussão pedagógica para as pautas de encontros e congressos internacionais, que buscavam propostas que permitissem elencar alternativas para o ensino em medicina e que se mostrava em processo acelerado de especialização precoce, a crescente utilização de tecnologias nos diagnósticos, efetivação da divisão do curriculo em dois ciclos (básico e profissional), o fim da medicina liberal e das práticas sociais, e o ensino e a prática médica individualizantes e centrada nos hospitais ${ }^{71}$.

No esteio destas discussões, e alimentando-as, na década de 1950 a Western Reserve University propõe uma organização curricular para seu curso médico que leva em consideração a distribuição dos conteúdos por sistemas do corpo humano, visando integrar as disciplinas básicas com as disciplinas clínicas, buscando a determinação de conteúdos essenciais que deveriam ser discutidos nestes espaços integrados dos sistemas corporais, evitando repetições e relacionando-os diretamente aos conteúdos práticos da clínica médica. Ainda que a divisão do corpo humano em sistemas orgânicos seja forma de pensar da concepção biomédica, esta permite integrar verticalmente os conteúdos das várias disciplinas sob um grande eixo de discussão, o do sistema em voga ${ }^{72}$. Esta experiência é inspiração para a reformulação do currículo médico em diversas escolas médicas ao longo dos anos 1960 e 1970, como Harvard, nos Estados Unidos $^{73}$, Mc Master, no Canadá e Maastrich, na Holanda ${ }^{74}$.

A Faculdade de Medicina deu sinais de acompanhar esta mudança ao incorporar o departamento de Medicina Preventiva e o internato na década de 1960, mas não alterou substancialmente o ensino oferecido, mantendo a estrutura das cátedras imutável; contudo, o grupo de professores propositores do CEM se inspira nas mudanças encetadas pelas escolas estrangeiras:

O Experimental representou uma ideia de você fazer um currículo muito baseado no que era na Western Reserve, num currículo médico integra-

70 GUIMARÃES, Maria Regina Cotrim. Os catedráticos de clinica médica e as propostas de reforma do ensino médico no Brasil nas décadas de 1950 e 1960. Tese de doutorado em História das Ciências e da Saúde, Fundação Oswaldo Cruz, Casa de Oswaldo Cruz. Rio de Janeiro, 2009, p. 187.

71 GUIMARÃES, Maria Regina Cotrim. Ensino médico nos anos 1950 e 1960: os catedráticos clínicos e o Relatório Flexner. "Usos do Passado". XII Encontro Regional de História. ANPUH, Rio de Janeiro, 2006, p. 1-9. Disponível em: http://www.rj.anpuh.org/resources/rj/Anais/2006/conferencias/Maria\%20Regina\%20Cotrim\%20Gu imaraes.pdf. Acesso em: 07 de fevereiro de 2015.

72 BARZANSKY, Barbara. The growth and divergence of the basic Science. In: BARZANSKY, Barbara M. GEVITZ, Norman (ed). Beyond Flexner: "Medical Education in the Twentieth Century". Chicago: British Library, 1992. P. 19-32.

73 ADELSTEIN, S. James; RAMOS, Myra S. Searching. In: TOSTESON, Daniel C.; ADELSTEIN, S. James; CARVER, Susan T. New pathways to medical education: Learning to Learn at Harvard Medical School. Massachusetts: Library of Congress. 1994. p. 13-29.

${ }^{74}$ IOCHIDA, Lúcia Christina. Metodologias problematizadoras no ensino em saúde. In: "Docência em saúde: temas e experiências". BATISTA, Nildo Alves; BATISTA, Sylvia Helena Souza da Silva (orgs). São Paulo: Editora Senac, 2004. P. 153-166. 
do, baseado em conjuntos de disciplinas que conversam ${ }^{75}$. Exatamente a origem é um pouco de certa forma nebulosa, porque uns queriam de fato modificar o currículo de acordo com o que se fazia na Northern Western, é uma das universidades americanas onde esse sistema teria sido adotado ou pelo menos se iniciado. Isso nos anos cinquenta e pouco que esse sistema foi adotado lá nos Estados Unidos ${ }^{76}$. O Experimental nasce dessa proposta mesmo. Muito inspirada nas reformas americanas. Tanto pedagógicas quanto de inserção dessas disciplinas novas no currículo, como a prevenção, prevenção comunitária, tal. E o professor Marcondes tinha ido pra Harvard, tinha estudado essa proposta lá, tinha visto, conhecido bem, e voltou trazendo a proposta pra cá ${ }^{77}$.

A inspiração norte-americana para a proposta do Curso Experimental de Medicina não é novidade para a construção curricular da Faculdade de Medicina da Universidade de São Paulo, que tem em seu histórico uma íntima relação com a filantropia norte-americana, através da Fundação Rockefeller, assim como busca nas instituições médicas daquele país formação para os seus professores ${ }^{78}$. A constância com que se faz a associação do Curso Experimental de Medicina aos cursos reformados norteamericanos, pode ser parte do discurso de apresentação e aculturação dos professores e estudantes ao Curso, mas também é reforçado pela sua divulgação na imprensa: O professor [Isaias Raw] diz que o sistema recém-instituído foi utilizado pela primeira vez há dez anos na Faculdade de Ciências Médicas de Western Reserve, em Cleaveland, EUA, e que o sistema atual de ensino pode ser comparado ao da Universidade de Harvard em $1928^{79}$.

Entretanto, o movimento reformador não acontecia apenas no exterior. No Brasil, algumas escolas médicas já acompanham esse movimento e mudanças podiam ser identificadas nos cursos médicos da Universidade Federal de Minas Gerais, da Universidade de Brasília e da própria Universidade de São Paulo de Ribeirão Preto ${ }^{80}$. Estas três experiências contribuem para a criação do Curso Experimental, de diferentes maneiras.

O curso médico da Universidade Federal de Minas Gerais estava em processo de modificação de suas práticas de ensino, concomitante ao processo de discussão do Curso Experimental. Reconhecida como uma experiência importante, o grupo de professores que assumiria os conteúdos de Bioquímica do CEM visita aquela Universidade para analisar e possivelmente aplicar em suas próprias aulas as iniciativas mineiras ${ }^{81}$.

A Universidade de Brasília trazia no seu projeto pedagógico a organização administrativo-pedagógico em departamentos, com professores contratados e não catedráticos, que ofereceriam suas disciplinas conforme os conteúdos necessários e não atrelados a carreiras; os estu-

75 Depoimento de antigo estudante da $5^{a}$ turma do Curso Experimental de Medicina para TAVANO, op. cit, 2015.

${ }^{76}$ Depoimento de antigo professor de Anatomia do Curso Experimental de Medicina para TAVANO, op. cit, 2015.

77 Depoimento de antigo professor de Medicina Preventiva do Curso Experimental de Medicina para TAVANO, op. cit, 2015.

78 MARINHO, Maria Gabriela Silva Martins da Cunha; MOTA, André (orgs). Caminhos e trajetos da filantropia cientifica em São Paulo: a Fundação Rockefeller e suas articulações no ensino, pesquisa e assistência para medicina e saúde (1916-1952). São Paulo: Casa de Soluções e Editora, 2013; TAVANO, op. cit, 2011; MARINHO, Maria Gabriela S. M. C. Elites em negociação: breve histórico dos acordos entre a Fundação Rockefeller e a Faculdade de Medicina de São Paulo. Bragança Paulista: EDUSF, 2003.

79 O Estado de São Paulo. Medicina vai abrir reforma. 24 de janeiro de 1968, p. 12.

80 EDLER, Flávio Coelho; FRÓES DA FONSECA, Maria Rachel. Coletânea de artigos originais e publicados nos boletins informativos da ABEM. Cadernos da ABEM. História da Educação Médica. v. 2, p. 6-26, 2005.

81 TAVANO, op. cit, 2015. 
dantes complementariam os seus estudos no sistema de créditos que não se mostrava em um alinhamento rígido e fixo, permitindo ao estudante escolher um percurso formativo distinto ${ }^{82}$. Esta influência é lembrada pelos antigos estudantes e professores do Curso: na realidade isso não era uma ideia original do pessoal daqui. Isso aí veio da Universidade de Brasilia que tinha um sistema de blocos tal, veio de lá, e o pessoal daqui abraçou a ideia ${ }^{83}$. Vale notar que Isaias Raw participou do projeto de elaboração do curso de medicina daquela Universidade, em contemporaneidade às discussões do projeto do Curso Experimental de Medicina ${ }^{84}$, ao que não se pode negar que possa haver certa retroalimentação de propostas, tal qual a circularidade de ideias com os norte-americanos.

Em Ribeirão Preto, a Universidade de São Paulo inicia suas atividades em 1952 com uma proposta diferenciada de organização e ensino:

Associação do regime de cátedras ao de departamentos, reduzindo o número de catedráticos (...); adoção do regime de tempo integral para todos os professores, inclusive os das clínicas, fato inédito nas escolas da área; a integração das atividades de ensino e pesquisa dos diversos departamentos/cátedras; a redução dos programas e do tempo dedicado à Morfologia, aumentando, correlativamente, a ênfase na Bioquímica, na Fisiologia e na Farmacologia; introdução de disciplinas até então inéditas no ensino médico do país, como Medicina Preventiva, Psicologia Médica e Medicina do Trabalho; a adoção de períodos semestrais para algumas disciplinas; a ênfase na atividade prática do ensino, em laboratórios, ambulatórios e hospitais ${ }^{85}$.

Assim, desde a década de 1950, acompanhando as tendências do ensino e pesquisa da área médica, a Faculdade de Medicina da Universidade de São Paulo de Ribeirão Preto apresentava uma estrutura administrativa distinta, com poucos catedráticos e todos os professores dedicados integralmente ao ensino. Com a redução da morfologia e aumento da Bioquímica, Fisiologia e Farmacologia, indica estar muito conectada às mudanças que se processam na forma de produção de conhecimento científico; porém, ela não se descuida da visão de integralidade de atendimento, estimulando a medicina social e a compreensão do ser humano como um todo. A Faculdade terá papel preponderante no Curso Experimental de Medicina, pois diversos dos professores contratados para o Curso tiveram parte de sua formação (ou toda ela) naquela Faculdade e trouxeram uma experiência de docência distinta: em Ribeirão Preto, no departamento de Morfologia, o chefe do departamento já vinha discutindo problemas de aula. Nós fizemos algumas aulas completamente diferentes, em que os estudantes interrompiam e começava a dar uma explicação ${ }^{86}$.

O movimento pela reforma do ensino médico, portanto, está presente no espaçotempo de proposição do Curso Experimental e pressiona a Faculdade de Medicina, não apenas porque as mudanças da área da medicina se insinuavam, não apenas porque a preocupação com o pedagógico se mostrava mais presente no ensino superior, mas também porque a $\mathrm{Fa}$ culdade estava perdendo seu papel de pioneira nesta nova fronteira a ser explorada. A Faculdade de Medicina era pioneira em técnicas e terapêuticas, mas não era pioneira em educação.

82 CUNHA, Luiz Antônio. A universidade crítica: o ensino superior na república populista. 3 ed. São Paulo: Unesp, 2007a.

83 Depoimento de antigo estudante da $3^{a}$ turma do Curso Experimental de Medicina para TAVANO, op. cit, 2015.

84 Ata da Congregação da FMUSP de 13 de maio de 1966, p. 141v.

85 CUNHA, op. cit, 2007a. p. 139.

86 Depoimento de antigo professor de Histologia do Curso Experimental de Medicina para TAVANO, op. cit, 2015. 
Portanto, o espaço-tempo de construção, proposição e aprovação do CEM se mostra imbricado por questões distintas que se mesclam e somam. Aliando as experiências internacionais aos exemplos nacionais de reformas do curso médico, os médicos reformistas se organizam em um grupo que aproveita a insistente demanda de aumento de vagas e de ocupação da Cidade Universitária, para apresentação de uma proposta diferente de formação médica, focada no aprendizado, no protagonismo do estudante na construção de seus conhecimentos e na aplicação de metodologias ativas de ensino. Uma experiência educacional única no campo dos currículos médicos.

\section{Considerações Finais}

Os propositores do Curso Experimental de Medicina imprimem no Curso sua própria trajetória/visão/ação de subversão, de preocupação com o social, suas próprias concepções de ser/saber/fazer médico e de construção de um percurso formativo. O lugar donde partem estes protagonistas é o filtro de seleção da construção do projeto Experimental de Medicina e ficará impresso no Curso como território inicial, território de partida que traz a reforma e a integração como motes.

As defesas pela integração espacial, pela ocupação da Cidade Universitária que o grupo de propositores enceta, marcam a proposta do Curso Experimental, não apenas na execução das aulas na Cidade Universitária, mas na utilização de espaços e professores de outras origens, de outras formações, e na busca de experiências educacionais em outros locais. A integração não se dá apenas fisicamente, mas se dá pelo reconhecimento de que outrem, externo à FMUSP, teria exatamente a mesma capacidade formativa dos estudantes do curso médico que um egresso da Faculdade teria. É significativa a presença de um professor-chave de formação completamente alheia à FMUSP: Guilherme Rodrigues da Silva representa esta integração. Com formação baiana, assume a Medicina Preventiva e Comunitária, que amalgamava a concepção fundante do Curso Experimental, de introduzir na formação a atenção primária e secundária, o atendimento ao enfermo "de pé" e a atenção médica a questões sociais e não apenas curativas.

Esta integração é multifacetada, assim como a possibilidade de reformar o ensino médico. Não há a pretensão de suplantar o Curso Tradicional e sim a intenção de aprimorá-lo, pois há clareza que o Curso Experimental se trata de uma experiência, que pode ou não dar certo a ser mantida, mas que, primariamente, é uma experiência que busca melhorar a formação médica da FMUSP.

Vale notar a habilidade dos propositores em atentar às contingências espaço-temporais que estão postas e utilizá-las a favor da aprovação de sua proposta. Não há ingenuidade, tampouco falta de projeto, nem mesmo falta de projeção e expressividade aos integrantes do grupo. O Curso Experimental é gestado, aprovado e implementado em um período de grandes conturbações políticas e sociais, incluindo um Golpe Militar. Entretanto, os professores que estão à sua frente têm clareza do tempo exato para que a sua proposta não fique no vazio e seja aprovada. Usar a "crise dos excedentes" como estopim e a influência política de Ulhôa Cintra para reforçar a imprescindibilidade da aprovação da proposta, demonstra que não havia intenção de se perder a briga junto ao convencionalismo da Congregação da FMUSP.

O Curso Experimental de Medicina é um produto do seu tempo, do alinhamento sócio-histórico-cultural de contingências e indivíduos que se dispuseram a modificar o ensino médico da Faculdade de Medicina da Universidade de São Paulo. 